\title{
Hip Fracture: The Choice of Surgery
}

\author{
Henrik Palm
}

\subsection{Aim of Surgery}

The aim of hip fracture surgery is to allow immediate mobilization with full weightbearing, aiming to achieve the previous level of function, ranging from maintaining normal walking in self-reliant elderly patients to pain relief in chronic bedridden nursing home residents. Three in four patients are expected to live beyond the first post-operative year, so proper surgery is required to alleviate an otherwise longstanding suboptimal functional level. Surgery is technically challenging, with body weight transfer through a broken oblique column, often with reduced bone quality due to osteoporosis - thus the risk of reoperation is high. A poorly operated hip fracture often leads to unequal leg length, pain and irreversible mobility loss, greatly influencing the quality of life.

\subsection{Fracture Types}

Hip fractures are divided into different types by the use of classification systems. A fracture classification should ideally have a high degree of reliability and reproducibility, be generally accepted, and have a prognostic validity in the clinical situation.

Historically, several classification systems have been proposed, but the following are the most commonly used in the literature. Hip fracture classifications are based

This chapter is a component of Part 2: Pillar I.

For an explanation of the grouping of chapters in this book, please see Chapter 1: 'The Multidisciplinary Approach to Fragility Fractures Around the World-An Overview'.

H. Palm $(\bowtie)$

Department of Orthopedics, Copenhagen University Hospital Bispebjerg,

Copenhagen, Denmark

e-mail: henrik.palm@ regionh.dk 
Fig.9.1 Antero-posterior radiograph of the right side proximal femur showing the anatomy and fracture positions. FNF femoral neck fracture, $T F$ trochanteric fracture, Sub-TF sub-trochanteric fracture, $L F W$ lateral femoral wall

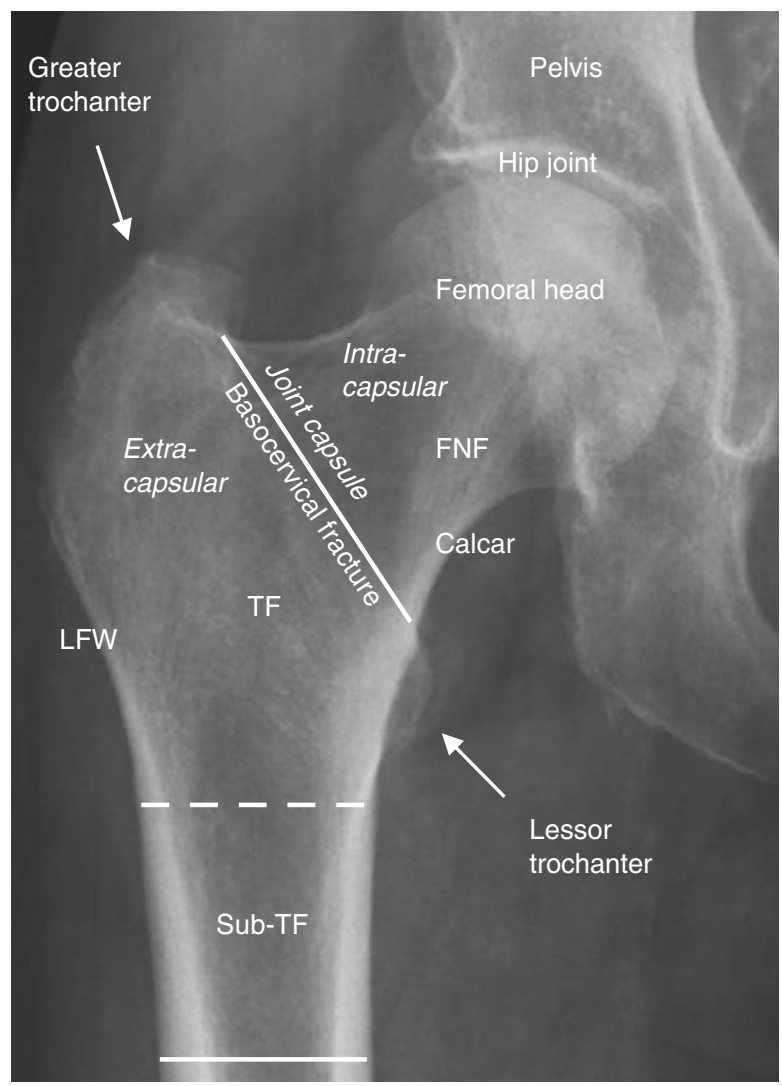

on radiographic fracture patterns, while previous hip surgery, arthritis, cancer, dysplasia, bone quality, soft tissue and pain are normally not taken into account.

Hip fractures cover proximal femoral fractures predominantly located up to $5 \mathrm{~cm}$ distal to the lesser trochanter and are classified by fracture anatomy on plain radiographs (Fig. 9.1), if necessary supplemented by CT or MRI [1].

The hip joint capsule divides fractures into two main categories with an almost equal patient distribution: (1) Intra-capsular femoral neck fractures and (2) extracapsular basicervical, trochanteric and sub-trochanteric fractures.

\subsubsection{Intra-capsular Fracture Types}

In a fragility fracture context, intra-capsular hip fractures are in fact through the femoral neck, as femoral head fractures are uncommon in the elderly.

Femoral neck fractures are at risk of non-union with/without mechanical collapse due to insufficient fixation and/or avascular necrosis of the femoral head. In adults, the femoral head is primarily supplied by the distal recurrent vessels entering the femur on the shaft side of the fracture. Avascular necrosis is caused by ischaemia hypothetically due to either a direct trauma to the arterial supply crossing the 


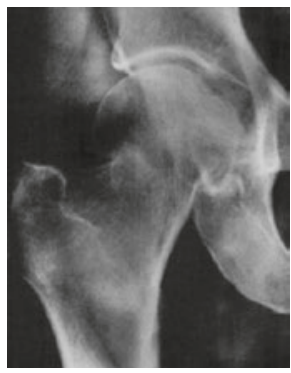

Stage I: Incomplete

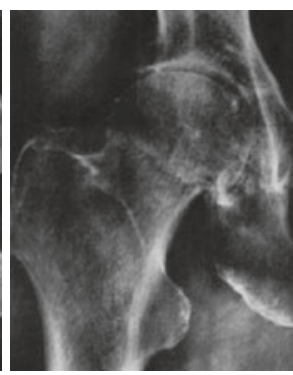

II: Complete

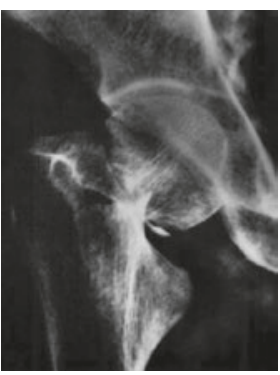

III: Partial displacement

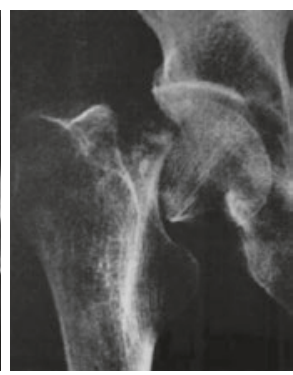

IV: Full displacement

Fig. 9.2 Garden's classification. (Reproduced with permission and copyright $($ ) of the British Editorial Society of Bone and Joint Surgery)

fracture-line or by a temporary arterial impingement, caused by vessel stretching or intra-capsular hematoma. Preoperative scintigraphy, electrode measurement and arthroscopic visualization of ischaemia have been tested but lack prognostic value. Since ischaemia could be temporary, acute reposition within hours (may be supplemented by hematoma emptying) has been suggested $[2,3]$.

Femoral neck fracture classification has historically been contentious with several different systems, primarily based on fracture displacement seen in the anterior-posterior radiographs. Garden's Classification (Fig. 9.2) has in the last half a century been the most widespread. Fractures are divided into four stages based on fracture displacement [4]. Garden's classification has only fair interobserver reliability when using all four stages, but moderate to substantial if dichotomized into just undisplaced (Garden I-II) or displaced (Garden III-IV) fractures [5].

In addition, a vertical fracture line in the anterior-posterior radiograph or posterior wall multi-fragmentation, femoral head size and posterior tilt angulation seen in the lateral radiograph are believed to influence outcome [6-9]. However, the dualism of undisplaced versus displaced (with reference to Gardens stages I-II vs. IIIIV) remains the most consistent predictor of failure and the most widespread fracture classification, with respectively around one-third and two-third of femoral neck fractures $[10,11]$.

\subsubsection{Extra-capsular Fracture Types}

Extra-capsular fractures are at risk of mechanical collapse and non-union due to insufficient fixation. The fracture line is anatomically located laterally to the nutrient vessels to the femoral head, so avascular necrosis is rarely seen, but muscle attachments often dislocate the fragments and bleeding into surrounding muscles can be severe and life-threatening. Classification systems are primarily based on fracture-line location and number of fragments.

Basicervical fractures are a few percent of borderline cases between the intraand extra-capsular fractures, anatomically positioned on the capsular attachment 
line. The AO/OTA classification describes them as intra-capsular, but biomechanically they behave like the extra-capsular fractures [12] — except for the risk of rotation of the medial segment due to lack of muscle attachments.

Trochanteric fractures cover the trochanteric area from the capsule until just below the lesser trochanter. The often-used unnecessary prefixes per-, inter- and trans- are undefined, confusing and unhelpful for classification.

The AO/OTA Classification (Fig. 9.3) from 1987 is nowadays the most widespread. It divides the 31-A trochanteric area into nine types by severity (1-2-3, each subtyped.1-.2-.3) [13].

Femur, proximal, pertrochanteric simple (only 2 fragments) (31-A1)

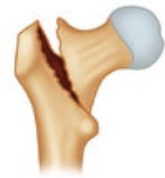

1. Along intertrochanteric line (31-A1.3)

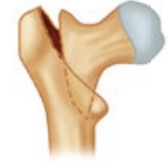

2. Through the greater trochanter (31-A1.1)

(1) nonimpacted

(2) impacted

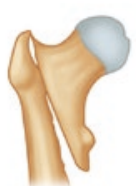

3. Below lesser trochanter (31-A1.2)

Femur, proximal, trochanteric fracture, pertrochanteric multifragmentary (always have posteromedial fragment with lessor trochanter and adjacent medial cortex (31-A2)

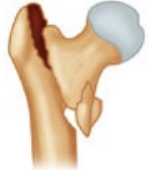

1. With 1 intermediate fragment (31-A2.1)

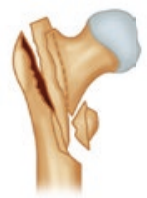
2. With several intermediate fragments (31-A2.2)

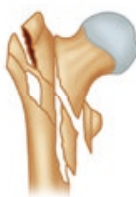

3. Extending more than $1 \mathrm{~cm}$ below lessor trochanter (31-A2.3)

Femur, proximal, trochanteric area, intertrochanteric fracture (31-A3)

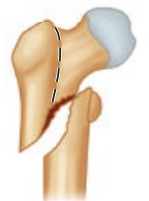

1. Simple oblique (31-A3.1)

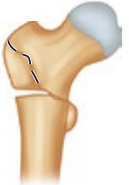

2. Simple transverse (31-A3.2)

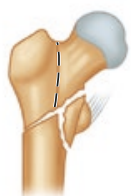

3. Multifragmentary

(31-A3.3)

(1) extending to greater

trochanter

(2) extending to neck

Fig. 9.3 AO/OTA Classification for trochanteric fractures (Reproduced with permission from J Orthop Trauma) 
Fracture type 31-A1 covers the simple two-part fractures, while 31-A2 demands a detached lesser trochanter, with an intact (31-A2.1) or a detached greater trochanter (31A2.2-3). 31-A3 covers fracture lines through the lateral femoral wall-defined as the lateral cortex distal to the greater trochanter-in which the subgroup 31-A3.1 represents the reverse fracture and 31-A3.2 the transversal, while the most comminuted 31-A3.3 fracture demands both a fractured lateral femoral wall and a detached lesser trochanter.

The AO/OTA classification covers most fractures within previous classification systems, except the few trochanteric fractures with a detached greater trochanter and an intact lesser trochanter. The reliability when using all nine types is poor, but increases to substantial if only classifying into the three main groups (A1-2-3) [14].

Subtrochanteric fractures are positioned distally to the trochanters, and constitute around $5 \%$ of all hip fractures. These have historically been classified by as many as 15 different systems, most often into the 8 types from 0 to $5 \mathrm{~cm}$ below the lesser trochanter by Seinsheimer or the 15 types from 0 to $3 \mathrm{~cm}$ in the AO/OTA classification for femoral shaft fractures, the type 32ABC(1-3).1 sub-division. A review doubts the value of such division and proposes simplicity into: (1) a stable two-part and unstable, (2) three-part and (3) more comminuted fractures from 0 to $5 \mathrm{~cm}$ below the lessor trochanter, without involvement of the trochanters. It however still has to be established whether this easier classification is useful and necessary for decision-making and prognosis $[13,15,16]$.

\subsection{Implants}

There are two major strategies for treating hip fractures, prosthesis or osteosynthesis. A prosthesis involves removing the fracture site, and replacing the femoral head with a hemi-arthroplasty or total hip arthroplasty, the latter also including an acetabular cup. An osteosynthesis involves reducing bone fragments to an acceptable position and retaining them until healing-usually with parallel implants, sliding hip screw or intramedullary nail (Fig. 9.4).

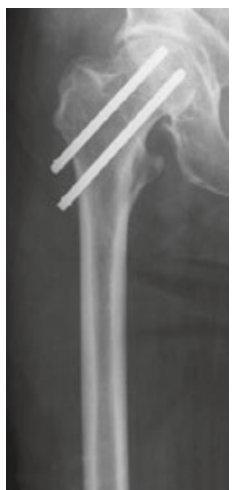

Parallel Implants

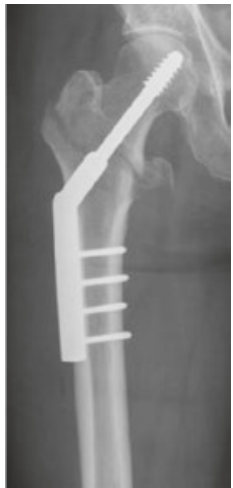

Sliding Hip Screw

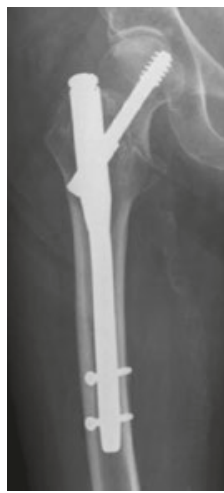

Intramedullary Nail

Osteosyntheses

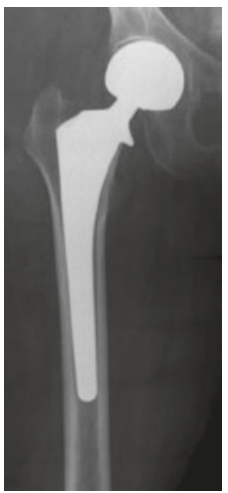

Hemi-Arthroplasty

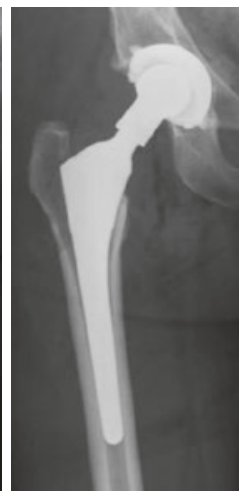

Total Hip Arthroplasty

Prostheses

Fig. 9.4 The main implant groups for hip fracture surgery 
Prostheses are inserted with the patient supine or lateral depending on the surgical approach, while osteosynthesis is always performed through one or more lateral approaches, with the patient supine on a traction table and the use of a radiographic image-intensifier. There are pros and cons for all implants, but all are dependent on proper use, which is why well-defined implant position measurements are needed for optimal evaluation of one implant against another.

Parallel implants are inserted with limited operative bleeding and soft tissue damage through a few lateral stab incisions or a single $<5 \mathrm{~cm}$ incision. In spite of many clinical and cadaver studies, choice (screws/hookpins) and number (2/3/4) of implants lack consensus [17]. Parallel implants permit fracture compression and they should be inserted as vertically as possible and in different head quadrants. Furthermore, the posterior implant should have posterior cortex contact and the inferior implant calcar contact to achieve three-point fixation that best supports weight transfer from (1) the subchondral bone to (2) a calcar seat and (3) a lateral femoral cortex counterpoint [18]. The main reasons for failure are non-union, with or without mechanical collapse, due to insufficient fixation and/or avascular necrosis. Also, a femoral neck shortened heling position is associated with poor functional outcome [19]. Salvage normally necessitates a hip prosthesis or, depending on the patient's demand, a simple removal of the femoral head. A new fall can result in fractures around the parallel implants, which should be reoperated with a sliding hip screw or an intramedullary nail.

Sliding hip screws have been the Gold Standard for treating trochanteric fractures for several decades-but have recently also gained ground for femoral neck fractures [17]. After reduction, the femoral head fragment is held by a large diameter screw, which can slide inside an approximately $135^{\circ}$ angle plate attached laterally to the femoral shaft. The implant is inserted under the lateral vastus muscle through a single lateral approach, around $10 \mathrm{~cm}$ long depending on chosen plate length.

To reduce the risk of cut-out of the screw into the hip joint, it should be positioned centrally or central-inferiorly in the femoral neck with the tip attached subchondrally in the femoral head, providing a short so-called tip-apex distance [20]. Beyond cut-out, the common reasons for failure are mechanical collapse, with or without non-union and a distal peri-implant fracture. Depending on femoral head bone status, salvage can be an intramedullary nail or a distally seated hip prosthesis.

Intramedullary nails have, during the last decade, outnumbered sliding hip screws as treatment for trochanteric fractures [21]. After reduction, the femoral head fragment is held by a large diameter screw, which can slide at an angle of approximately $130^{\circ}$ through an intramedullary nail with 1-2 distal locking screws. The nail is inserted at the greater trochanter tip, through a 5-cm lateral incision, with the sliding and locking screw(s) inserted by use of a guide through stab incisions in the lateral vastus muscle. A central-inferior position in the femoral head and a short tip-apex distance for the threaded types is important, while the new bladed types might need more distance $[22,23]$. 
Some old nails had a reputation for risking a shaft fracture, but newer nails have moved beyond this, although the many new smaller designs, with different screw, blade, sleeve, locking and anti-rotation mechanisms, lack convincing clinical evidence so far $[24,25]$.

Reasons for failure are the same as for the sliding hip screws, and salvage can be a distally seated hip prosthesis for bone collapse. In case of a distal periimplant fracture, a longer nail or a condylar plate can be used, depending on the nail length.

Prostheses involve a metal femoral head replacement attached by a stem seated in the shaft cavity. To fit individual patients' anatomy, implants are modular and assembled during surgery; thus mono-blocks are no longer recommended [26]. Reoperations are primarily caused by repeated dislocations or by a peri-prosthetic fracture (produced during insertion or subsequent to a new fall). For dislocations, closed reduction is the norm, but reposition or modification with a low-range-ofmotion constrained liner is necessary in recurrent cases. Peri-prosthetic fractures are treated with circumferential wires and/or a plate, and a loose prosthesis is changed or removed depending on the patient's demands.

Hemi-arthroplasties (HA) traditionally have reduced dislocation rate, shorter operating time and less blood loss than a total hip arthroplasty. Reports of acetabular chondral erosion, following unipolar HA, have encouraged bipolar heads with an additional ball joint - their efficiency is, however, still debated [27-29].

Total Hip Arthroplasties (THA) also replace the acetabular cartilage, theoretically a source of pain and thus reduced functional ability. THAs might provide a better result than HAs in active, independent living, and cognitively intact patients, but more studies are warranted [28, 30-33]. Despite the higher implant price, the total cost of using THA could be lower when taking complications and function into account, in the healthiest patients [34]. THAs, however, have an increased dislocation risk [28, 30, 31, 35], which might be reduced by the technically demanding new dual-mobility type [36-38].

Beyond optimal implant positioning, the dislocation rate following both HA and THA might be reduced to $1-3 \%$ of patients if using the antero-lateral approach, compared to $4-14 \%$ if using the postero-lateral approach, although the latter can probably be improved by an optimal capsular and muscle repair [3941]. The only randomized study, however, found no difference in dislocation rate between the two methods [42], and a register study found that the consequences of surgical approach for soft tissue, pain and mobility might be minimal [43]. It may be that dual-mobility cups can justify the continued use of the postero-lateral approach [36-38].

Cementation is associated with more dislocations in some studies but less in others. Cementation seems to improve patient mobility, reduce pain and the rate of peri-prosthetic fractures (1-7\% for uncemented prostheses), although only a few studies include the newer hydroxyapatite-coated surfaces. Cementation probably increases risk of air embolism, blood loss and operation time, but registries have shown that a higher acute mortality appears to equilibrate after a couple of months [2, 28, 29, 44-46]. 


\subsection{Surgical Management}

Patients should receive their operation as soon as possible, because the negative impact on body functions, while waiting for surgery, appears to be significant. Surgery on the day of, or the day after admission (less than $36 \mathrm{~h}$ ) is recommended, although studies to prove this are difficult, because stratification by comorbidities is challenging [47-51].

Surgical drains [52], and pre-operative traction is no longer recommended [53]. Conservative treatment should be avoided in modern healthcare systems [54], except in the case of few terminally ill patients who can be kept pain-free by analgesics in their last few days of life.

Patients sustaining a metastatic fracture should be identified, the cancer investigated and the proximal femur fixed in a way that takes into account the growing cancer, normally by use of a long nail or a distally seated THA.

Prophylactic antibiotic treatment should be given. Deep infection is rare (Table 9.1), but potentially devastating, often with several procedures and implant removal. While treating the infection, an external fixator can be used to keep extracapsular fractures reduced. Predictors of infections are primarily the surgeon's experience and the operation duration $[55,56]$.

\subsubsection{Intra-capsular Operations}

The overall choice stands between (1) femoral head removal and insertion of a prosthesis, or (2) femoral head preservation by internal fixation, wherein the main overall predictor for failure is initial fracture displacement [3]. However, patient age, co-morbidity, mobility demands and so on should also be taken into account in the choice of implant. Patients should be asked about pre-fracture hip pain and a THA is chosen if hip arthritis coexists.

Table 9.1 Overall rates of surgical complications

\begin{tabular}{|c|c|c|c|c|c|c|c|}
\hline & $\begin{array}{l}\text { Deep } \\
\text { infection } \\
(\%)\end{array}$ & $\begin{array}{l}\text { Non- } \\
\text { union } \\
\text { and } \\
\text { cut- } \\
\text { out } \\
(\%)\end{array}$ & $\begin{array}{l}\text { Avascular } \\
\text { necrosis } \\
(\%)\end{array}$ & $\begin{array}{l}\text { Distal } \\
\text { fracture } \\
(\%)\end{array}$ & $\begin{array}{l}\text { Dislocation } \\
(\%)\end{array}$ & $\begin{array}{l}\text { Aseptic } \\
\text { loosening } \\
(\%)\end{array}$ & $\begin{array}{l}\text { Reoperation } \\
(\%)\end{array}$ \\
\hline $\begin{array}{l}\text { Undisplaced } \\
\text { FNF, IF }\end{array}$ & $\approx 1$ & $5-10$ & $4-10$ & $<1$ & - & - & $8-12$ \\
\hline $\begin{array}{l}\text { Displaced } \\
\text { FNF, IF }\end{array}$ & $\approx 1$ & $20-35$ & $5-20$ & $<1$ & - & - & $15-35$ \\
\hline $\begin{array}{l}\text { FNF, } \\
\text { Prosthesis }\end{array}$ & $1-7$ & - & - & $1-7$ & $1-14$ & $1-3$ & $2-15$ \\
\hline $\begin{array}{l}\text { Extra- } \\
\text { capsular }\end{array}$ & $\approx 1$ & $1-10$ & $<1$ & $1-4$ & - & - & $2-10$ \\
\hline
\end{tabular}

$F N F$ femoral neck fracture, $I F$ internal fixation 
Undisplaced femoral neck fractures may be complicated by non-union, with or without fracture collapse and, after a minimum of 3-6 months, radiographically evident avascular necrosis of the femoral head (Table 9.1). Around three-quarters of the undisplaced fractures are treated with parallel screws or pins, which appears to be adequate $[3,17]$. The sliding hip screw is comparable and enables a more stable fixation due to the fixed angle attachment when three-point fixation is unachievable due to a vertical and/or basal fracture line-but necessitates a larger incision. Also, posterior tilt might increase the reoperation rate [7,8], suggesting that this may be an indication for prosthesis, rather than osteosynthesis.

Displaced femoral neck fractures are followed by the same complications after internal fixation as the undisplaced-but at a higher rate (Table 9.1).

If using internal fixation, the fracture must be anatomically reduced within a short time and the implants optimally positioned. Prostheses are now the most common treatment for displaced fractures, with improved results (Table 9.1) varying with the approach, cementation and THA/HA [2, 17, 18, 21, 44, 45, 57, 58].

A large number of studies report a significantly lower reoperation rate following a prosthetic replacement. Newer studies also find less pain, better hip function and higher patient satisfaction after a prosthesis. However, this is at the expense of a greater primary operation (operating time, soft tissue damage, blood loss and impact on body functions) resulting in a higher immediate mortality. Fortunately, this appears to equilibrate later [2, 29, 57-59].

Using internal fixation for all displaced fractures, with the insertion of a prosthesis later if required, is not recommended as a salvage prosthesis insertion has a much higher complication risk than a primary. Prostheses, however, have a shorter lifetime in mobile young patients who might outlive their prosthesis once or more. It has therefore been suggested to use an internal fixation in the younger patients, THA in active patients aged around 65-80 years and HA in the oldest. [2, 29, $35,60]$.

The subgroup of demented patients might benefit more from internal fixationtheir functional scores are generally low-but the literature is so far limited [61, 62]. Osteosynthesis in most fragile patients, who are demented or have a high risk of dying on the operation table, should however be used with caution, as the fixation often turns out to be inadequate and painful in the short term-requiring a reoperation-if the patients live longer than expected. In a few selected bedridden, oldest patients, a simple removal of the femoral head can be chosen as the primary procedure to reduce fracture pain and eliminate complications.

\subsubsection{Extra-capsular Operations}

Basicervical fractures are treated with a sliding hip screw, attached to a short lateral plate. Parallel implants are insufficient because of the lack of implant support by the calcar bone area [12].

Trochanteric fractures may be complicated by a non-union or mechanical collapse in $1-10 \%$ of patients. The pull of muscles often displaces fragments, while a 
near-anatomical reduction is necessary for the majority of weight to pass through the bone. Use of retractors and/or a posterior-reduction device on the fracture table is recommended to prevent sagging of the fracture.

During the early post-operative months, an inadequate reduction and implant position may lead to femoral shaft medialization and femoral head varus position with risk of a screw cut-out, pain and a shortened femoral neck- and leglength. The overall rate of reoperation is 2-10\%. [25, 63-65]. A salvage prosthesis can be inserted primarily, but this is challenging due to the damaged bone stock.

The choice of implant is between the sliding hip screw and an intramedullary nail but, after many cohort studies and more than 40 RCTs since the past three decades, the comparison remains inconclusive overall. The current status appears to be that, although the sliding hip screw remains the recommended implant, nails might have an advantage on mobility or in the more unstable trochanteric fracture $[24,66,67]$. The Norwegian national registry reported fewer reoperations after sliding hip screws in 7643 stable (AO/OTA type 31A1) and after nails in 2716 unstable trochanteric fractures (AO/OTA type 31A3) [64, 65]. However, a systematic review of the six RCTs on a total of 265 patients with AO/OTA type A3 fractures found comparable fracture healing complication rates for sliding hip screws and intramedullary nails-and more RCTs on fracture subgroups are warranted [68].

Often lateralization and femoral neck shortening are seen following the unstable trochanteric fractures, probably due to a lack of a buttress from the lateral femoral wall. A trochanteric buttress shield might prevent lateralization, but the evidence is not convincing and the method demands a much larger incision than simply inserting the well-known intramedullary femoral nail. The sliding hip screw might be insufficient for fractures with a detached greater trochanter (AO/OTA type A2.2 and A2.3) as the resulting thin lateral femoral wall is at risk of per-operative fracture. The integrity of the lesser trochanter does not seem to influence outcome, and unstable trochanteric fractures should probably thus be defined by a detached greater trochanter or a lateral femoral wall fracture (AO/OTA type 31A.2.2-2.3 + A3) $[69,70]$.

So far knowledge is limited on whether the use of the longest possible nail can reduce risk of later shaft-fractures, although femoral shaft bending, entry-point and distal locking appears more challenging in long nails [71].

Sub-trochanteric fractures are nowadays most often treated with a long nail, which is probably beneficial with reoperation rates declining by $5-15 \%$. Most literature, however, also included the AO/OTA 31A3 fractures, due to difficulties of differentiation and more knowledge is needed. Circumferential wires can be added for keeping the oblique and comminuted fractures reduced with a low risk of bonenecrosis $[15,72]$. 


\subsection{Surgical Algorithms and National Guidelines}

As indicated earlier, the published evidence in the last decades has created a degree of consensus for the surgical treatment of hip fractures. In everyday clinical practice, the exact choice of implant however often remains uncertain, and an easily used surgical algorithm for all hip fracture patients might be warranted.

Younger, less experienced surgeons probably feel more confident when guided by a strict algorithm, while older surgeons could feel that their individual right of choice is being restricted. It is, however, important to underline that a treatment algorithm does not negate the individual surgeon's responsibility for the individual patient. A surgeon still has the right and duty, now and then, to defy a guideline due to individual circumstances, but the decision to do so should be justified in the patient record.

Creating an algorithm that embraces the heterogeneous group of hip fracture patients is challenging, and the balance between detail and usability must be considered. Many published articles recommend treatment for some aspects, but only a few authors have published comprehensive decision-tree algorithms for hip fracture surgery-among which the simple, exhaustive and exclusive Copenhagen Algorithm (Fig. 9.5) appears to be the best scientifically evaluated $[9,73]$.

National guidelines including surgery have emerged in Australia, New Zealand, United States and most European countries during the last decades. Consensus is widespread for some overall recommendations based on the same evidence.

Among the intra-capsular fractures, all recommend internal fixation for undisplaced femoral neck fractures and to some extent prosthetic replacement for the displaced in elderly patients. Among the extra-capsular fractures, the sliding hip screw is recommended for the stable (often defined as AO/OTA type A1) while a nail is recommended for the unstable fractures (often defined as AO/OTA type A3 and further distal). The purpose of national guidelines is to recommend evidencebased surgical treatment for improving outcome. National hip fracture registries have gained ground, especially in the last decades, to enable continued evaluation of treatment quality and the identification of positive and negative outliers. [10, $73,74]$.

The multidisciplinary global fragility fracture network has now the strategic focus of facilitating national (or regional) consensus guidelines including quality standards and systematic performance measurement-and offers an easily used minimum data set for hip fracture audit [74]. Hopefully, such knowledge dissemination not only helps to overcome barriers to implementation, but also to globally spread evidence-based national guidelines, standards and registries for improving the surgical quality. 


\section{Fracture type \\ Femoral Neck Fractures \\ Undisplaced

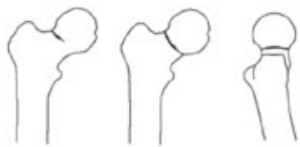

Garden Type I-II with $<20^{\circ}$ post. tilt

Displaced
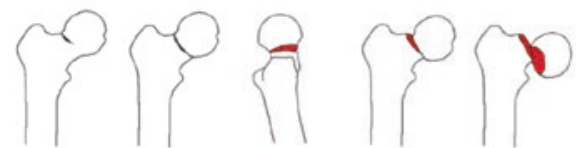

Garden Type I-II with $\square 20^{\circ}$ post. tilt + Garden Type III-IV

\section{Vertical}

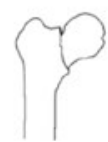

\section{Extracapsular Fractures}

Basocervical

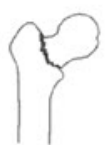

Stable trochanteric
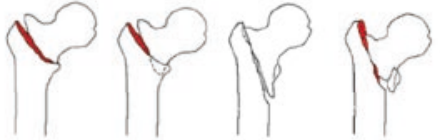

AO/OTA Type Al.1, A1.2, A1.3, A2.1

Unstable trochanteric
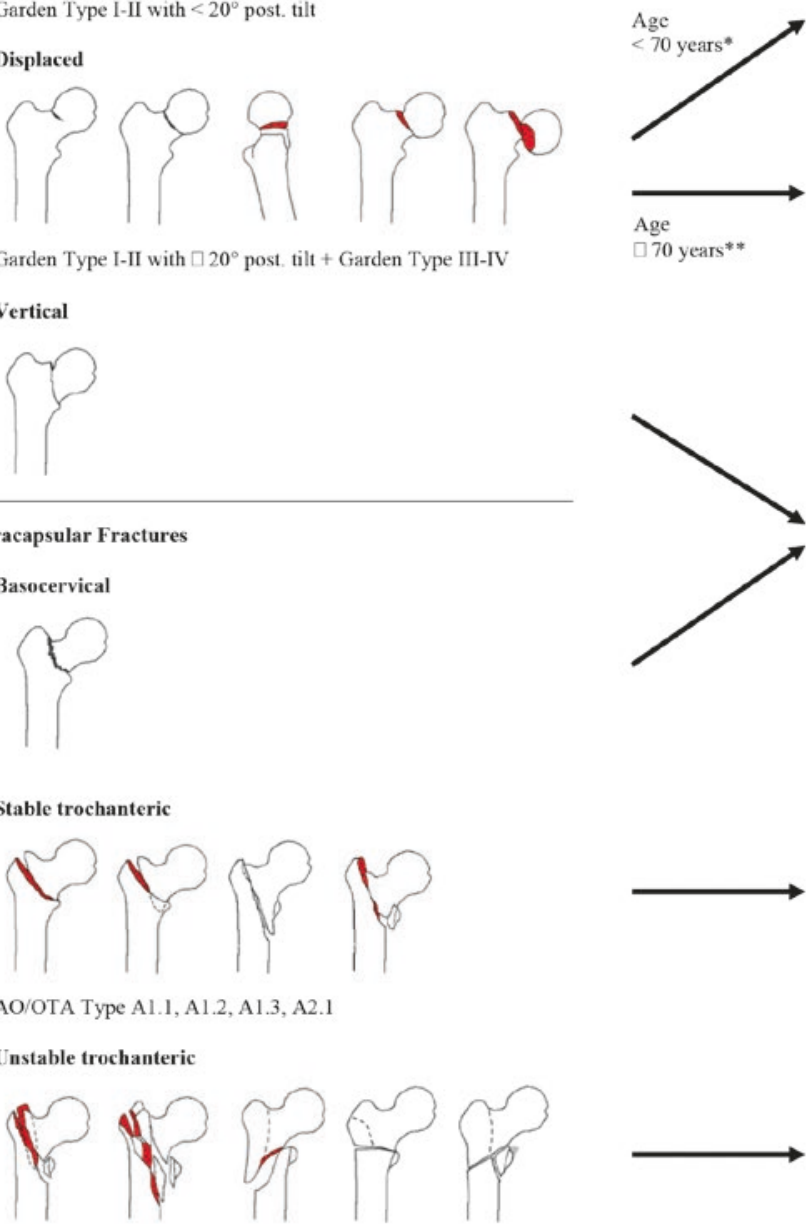

Operation type

Parallel Implants
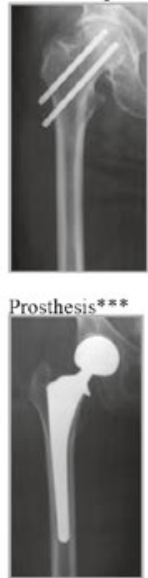

2-hole SHS

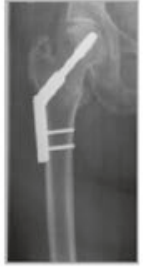

4-hole SHS

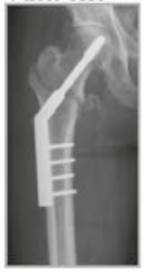

IM-nail****

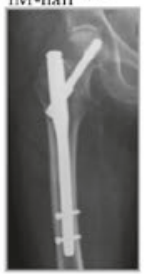

AO/OTA Type A2.2, A2.3, A3.1, A3.2, A3.3

"Prosthesis, if not fully reducible on traction table. ${ }^{* *}$ Femoral head removal, if no pre-fracture mobility. ${ }^{* * *}$ Mandatory supervision of junior residents. SHS: Sliding hips screw. IM-nail: Intramedullary nail.

Fig. 9.5 An algorithm for hip fracture surgery (Reproduced with permission from Acta Orthop) 


\section{References $^{1}$}

1. Cannon J, Silvestri S, Munro M (2009) Imaging choices in occult hip fracture. J Emerg Med $37: 144-152$

2. Heetveld MJ, Rogmark C, Frihagen F, Keating J (2009) Internal fixation versus arthroplasty for displaced femoral neck fractures: what is the evidence? J Orthop Trauma 23:395-402

3. Loizou CL, Parker MJ (2009) Avascular necrosis after internal fixation of intracapsular hip fractures; a study of the outcome for 1023 patients. Injury 40:1143-1146

4. Garden RS (1961) Low-angle fixation in fractures of the femoral neck. J Bone Joint Surg (Br) 43-B:647-663

5. Gašpar D, Crnković T, Durovic D, Podsednik D, Slišurić F (2012) AO group, AO subgroup, Garden and Pauwels classification systems of femoral neck fractures: are they reliable and reproducible? Med Glas (Zenica) 9:243-247

6. Khan SK, Khanna A, Parker MJ (2009a) Posterior multifragmentation of the femoral neck: does it portend a poor outcome in internally fixed intracapsular hip fractures? Injury 40:280-282

7. Okike K, Udogwu UN, Isaac M, Sprague S, Swiontkowski MF, Bhandari M, Slobogean GP, FAITH Investigators (2019) Not all Garden-I and II femoral neck fractures in the elderly should be fixed: effect of posterior tilt on rates of subsequent arthroplasty. J Bone Joint Surg Am 101(20): 1852-1859

8. Palm H, Gosvig K, Krasheninnikoff M, Jacobsen S, Gebuhr P (2009) A new measurement for posterior tilt predicts reoperation in undisplaced femoral neck fractures: 113 consecutive patients treated by internal fixation and followed for 1 year. Acta Orthop 80(3):303-307

9. Palm H, Krasheninnikoff M, Holck K, Lemser T, Foss NB, Jacobsen S, Kehlet H, Gebuhr P (2012) A new algorithm for hip fracture surgery. Acta Orthop 83(1):26-30

10. National Hip Fracture Database (2019) National report. http://www.nhfd.co.uk. Accessed 15 Feb 2020

11. Zlowodzki M, Bhandari M, Keel M, Hanson BP, Schemitsch E (2005) Perception of Garden's classification for femoral neck fractures: an international survey of 298 orthopaedic trauma surgeons. Arch Orthop Trauma Surg 125:503-505

12. Mallick A, Parker MJ (2004) Basal fractures of the femoral neck: intra- or extra-capsular. Injury 35:989-993

13. Marsh JL, Slongo TF, Agel J, Broderick JS, Creevey W, DeCoster TA, Prokuski L, Sirkin MS, Ziran B, Henley B, Audigé L (2007) Fracture and dislocation classification compendium-2007: orthopaedic trauma association classification, database and outcomes committee. J Orthop Trauma 21(Suppl 10):S1-S133

14. Pervez H, Parker MJ, Pryor GA, Lutchman L, Chirodian N (2002) Classification of trochanteric fracture of the proximal femur: a study of the reliability of current systems. Injury 33:713-715

15. Loizou CL, McNamara I, Ahmed K, Pryor GA, Parker MJ (2010) Classification of subtrochanteric femoral fractures. Injury 41:739-745

16. Seinsheimer F (1978) Subtrochanteric fractures of the femur. J Bone Joint Surg 60(3):300-306

17. Parker MJ, Gurusamy KS (2011) Internal fixation implants for intracapsular hip fractures in adults (Review). Cochrane Database Syst Rev. https://doi.org/10.1002/14651858.CD001467

18. Schep NWL, Heintjes RJ, Martens EP, van Dortmont LMC, van Vugt AB (2004) Retrospective analysis of factors influencing the operative result after percutaneous osteosynthesis of intracapsular femoral neck fractures. Injury 35:1003-1009

\footnotetext{
${ }^{1}$ This book chapter is an updated version of: Palm H (2016) An algorithm for hip fracture surgery. Doctor of Medical Science. Dissertation. Copenhagen University. ISBN 978-87-998,922-0-4.
} 
19. Felton J, Slobogean GP, Jackson SS, Della Rocca GJ, Liew S, Haverlag R, Jeray KJ, Sprague SA, O'Hara NN, Swiontkowski M, Bhandari M (2019) Femoral neck shortening after hip fracture fixation is associated with inferior hip function: results from the FAITH trial. J Orthop Trauma 33(10):487-496

20. Baumgaertner MR, Solberg BD (1997) Awareness of tip-apex distance reduces failure of fixation of trochanteric fractures of the hip. J Bone Joint Surg (Br) 79-B:969-971

21. Rogmark C, Spetz C, Garellick G (2010) More intramedullary nails and arthroplasties for treatment of hip fractures in Sweden. Acta Orthop 81:588-592

22. Nikoloski AN, Osbrough AL, Yates PJ (2013) Should the tip-apex distance (TAD) rule be modified for the proximal femoral nail antirotation (PFNA)? A retrospective study. J Orthop Surg Res 8:35

23. Rubio-Avila J, Madden K, Simunovic N, Bhandari M (2013) Tip to apex distance in femoral intertrochanteric fractures: a systematic review. J Orthop Sci 18:592-598

24. Bhandari M, Schemitsch E, Jönsson A, Zlowodzki M, Haidukewych GJ (2009) Gamma nails revisited: gamma nails versus compression hip screws in the management of intertrochanteric fractures of the hip: a meta-analysis. J Orthop Trauma 23:460-464

25. Queally JM, Harris E, Handoll HHG, Parker MJ (2014) Intramedullary nails for extracapsular hip fractures in adults (Review). Cochrane Database Syst Rev. https://doi.org/10.1002/14651858. CD004961.pub4

26. Rogmark C, Leonardsson O, Garellick G, Kärrholm J (2012) Monoblock hemiarthroplasties for femoral neck fractures - a part of orthopaedic history? Analysis of national registration of hemiarthroplasties 2005-2009. Injury 43:946-949

27. Jia Z, Ding F, Wu Y, Li W, Li H, Wang D, He Q, Ruan D (2015) Unipolar versus bipolar hemiarthroplasty for displaced femoral neck fractures: a systematic review and meta-analysis of randomized controlled trials. J Orthop Surg Res 10:8

28. Parker MJ, Gurusamy KS, Azegami S (2010) Arthroplasties (with and without bone cement) for proximal femoral fractures in adults (Review). Cochrane Database Syst Rev. https://doi. org/10.1002/14651858.CD001706.pub4

29. Rogmark C, Leonardsson O (2016) Hip arthroplasty for the treatment of displaced fractures of the femoral neck in elderly patients. Bone Joint J 98-B:291-297

30. Bhandari M, Einhorn TA, Guyatt G, Schemitsch EH, Zura RD, Sprague S, Frihagen F, GuerraFarfán E, Kleinlugtenbelt YV, Poolman RW, Rangan A, Bzovsky S, Heels-Ansdell D, Thabane L, Walter SD, Devereaux PJ (2019) Total hip arthroplasty or hemiarthroplasty for hip fracture. N Engl J Med 381(23):2199-2208

31. Burgers PT, Van Geene AR, Van den Bekerom MP, Van Lieshout EM, Blom B, Aleem IS, Bhandari M, Poolman RW (2012) Total hip arthroplasty versus hemiarthroplasty for displaced femoral neck fractures in the healthy elderly: a meta-analysis and systematic review of randomized trials. Int Orthop 36:1549-1560

32. Hansson S, Nemes S, Kärrholm J, Rogmark C (2017) Reduced risk of reoperation after treatment of femoral neck fractures with total hip arthroplasty. Acta Orthop 88(5):500-504

33. Parker MJ, Cawley S (2019) Treatment of the displaced intracapsular fracture for the 'fitter' elderly patients: a randomised trial of total hip arthroplasty versus hemiarthroplasty for 105 patients. Injury 50(11):2009-2013

34. Slover J, Hoffman MV, Malchau H, Tosteson ANA, Koval KJ (2009) A cost-effectiveness analysis of the arthroplasty options for displaced femoral neck fractures in the active, healthy, elderly population. J Arthroplast 24:854-860

35. Hansson S, Bülow E, Garland A, Kärrholm J, Rogmark C (2019) More hip complications after total hip arthroplasty than after hemi-arthroplasty as hip fracture treatment: analysis of 5,815 matched pairs in the Swedish Hip Arthroplasty Register. Acta Orthop 18:1-6 
36. Adam P, Philippe R, Ehlinger M, Roche O, Bonnomet F, Molé D, Fessy MH, French Society of Orthopaedic Surgery and Traumatology (SoFCOT) (2012) Dual mobility cups hip arthroplasty as a treatment for displaced fracture of the femoral neck in the elderly. A prospective, systematic, multicenter study with specific focus on postoperative dislocation. Orthop Traumatol Surg Res 98:296-300

37. Bensen AS, Jakobsen T, Krarup N (2014) Dual mobility cup reduces dislocation and reoperation when used to treat displaced femoral neck fractures. Int Orthop 38:1241-1245

38. Jobory A, Kärrholm J, Overgaard S, Becic Pedersen A, Hallan G, Gjertsen JE, Mäkelä K, Rogmark C (2019) Reduced revision risk for dual-mobility cup in total hip replacement due to hip fracture: a matched-pair analysis of 9,040 cases from the Nordic Arthroplasty Register Association (NARA). J Bone Joint Surg Am 101(14):1278-1285

39. Enocson A, Tidermark J, Tornkvist H, Lapidus LJ (2008) Dislocation of hemiarthroplasty after femoral neck fracture: better outcome after the anterolateral approach in a prospective cohort study on 739 consecutive hips. Acta Orthop 79:211-217

40. Enocson A, Hedbeck CJ, Tidermark J, Pettersson H, Ponzer S, Lapidus LJ (2009) Dislocation of total hip replacement in patients with fractures of the femoral neck. Acta Orthop 80:184-189

41. Pellicci PM, Bostrom M, Poss R (1998) Posterior approach to total hip replacement using enhanced posterior soft tissue repair. Clin Orthop Relat Res 355:224-228

42. Parker MJ (2015) Lateral versus posterior approach for insertion of hemiarthroplasties for hip fractures: a randomised trial of 216 patients. Injury 46(6):1023-1027

43. Leonardsson O, Rolfson O, Rogmark C (2016) The surgical approach for hemiarthroplasty does not influence patient-reported outcome: a national survey of 2118 patients with one-year follow-up. Bone Joint J 98-B(4):542-547

44. Imam MA, Shehata MSA, Elsehili A, Morsi M, Martin A, Shawqi M, Grubhofer F, Chirodian N, Narvani A, Ernstbrunner L (2019) Contemporary cemented versus uncemented hemiarthroplasty for the treatment of displaced intracapsular hip fractures: a meta-analysis of forty-two thousand forty-six hips. Int Orthop 43(7):1715-1723

45. Kristensen TB, Dybvik E, Kristoffersen M, Dale H, Engesæter LB, Furnes O, Gjertsen JE (2020) Cemented or uncemented hemiarthroplasty for femoral neck fracture? Data from the norwegian hip fracture register. Clin Orthop Relat Res 478(1):90-100

46. Talsnes O, Vinje T, Gjertsen JE, Dahl OE, Engesæter LB, Baste V, Pripp AH, Reikerås O (2013) Perioperative mortality in hip fracture patients treated with cemented and uncemented hemiprosthesis: a register study of 11,210 patients. Int Orthop 37:1135-1140

47. Bretherton CP, Parker MJ (2015) Early surgery for patients with a fracture of the hip decreases 30-day mortality. Bone Joint J 97-B:104-108

48. HIP ATTACK Investigators (2020) Accelerated surgery versus standard care in hip fracture (HIP ATTACK): an international, randomised, controlled trial. Lancet 395:698-708

49. Khan SK, Kalra S, Khanna A, Thiruvengada MM, Parker MJ (2009b) Timing of surgery for hip fractures: a systematic review of 52 published studies involving 291,413 patients. Injury 40:692-697

50. Moja L, Piatti A, Pecoraro V, Ricci C, Virgili G, Salanti G, Germagnoli L, Liberati A, Banfi G (2012) Timing matters in hip fracture surgery: patients operated within 48 hours have better outcomes. A meta-analysis and meta-regression of over 190,000 patients. PLoS One 7:e46175

51. Simunovic N, Devereaux PJ, Sprague S, Guyatt GH, Schemitsch E, Debeer J, Bhandari M (2010) Effect of early surgery after hip fracture on mortality and complications: systematic review and meta-analysis. CMAJ 182:1609-1616

52. Clifton R, Haleem S, Mckee A, Parker MJ (2008) Closed suction surgical wound drainage after hip fracture surgery: a systematic review and meta-analysis of randomised controlled trials. Int Orthop 32:723-727 
53. Handoll HHG, Queally JM, Parker MJ (2011) Pre-operative traction for hip fractures in adults (Review). Cochrane Database Syst Rev. https://doi.org/10.1002/14651858.CD000168.pub3

54. Handoll HHG, Parker MJ (2008) Conservative versus operative treatment for hip fractures in adults (Review). Cochrane Database Syst Rev. https://doi.org/10.1002/14651858. CD000337.pub2

55. Harrison T, Robinson P, Cook A, Parker MJ (2012) Factors affecting the incidence of deep wound infection after hip fracture surgery. J Bone Joint Surg (Br) 94-B:237-240

56. Noailles T, Brulefert K, Chalopin A, Longis PM, Gouin F (2016) What are the risk factors for post-operative infection after hip hemiarthroplasty? Systematic review of literature. Int Orthop 40(9): 1843-1848

57. Lu-Yao G, Keller R, Littenberg B, Wennberg J (1994) Outcomes after displaced fractures of the femoral neck. A meta-analysis of one hundred and six published reports. J Bone Joint Surg Am 76-A:15-25

58. Parker MJ, Gurusamy KS (2006) Internal fixation versus arthroplasty for intracapsular proximal femoral fractures in adults (Review). Cochrane Database Syst Rev:CD001708

59. Rogmark C, Johnell O (2006) Primary arthroplasty is better than internal fixation of displaced femoral neck fractures: a meta-analysis of 14 randomized studies with 2,289 patients. Acta Orthop 77:359-367

60. Mahmoud SS, Pearse EO, Smith TO, Hing CB (2016) Outcomes of total hip arthroplasty, as a salvage procedure, following failed internal fixation of intracapsular fractures of the femoral neck: a systematic review and meta-analysis. Bone Joint J 98-B(4):452-460

61. Hebert-Davies J, Laflamme G-Y, Rouleau D (2012) Bias towards dementia: are hip fracture trials excluding too many patients? A systematic review. Injury 43:1978-1984

62. Van Dortmont LM, Douw CM, van Breukelen AM, Laurens DR, Mulder PG, Wereldsma JC, van Vugt AB (2000) Outcome after hemi-arthroplasty for displaced intracapsular femoral neck fracture related to mental state. Injury 31:327-331

63. Chirodian N, Arch B, Parker MJ (2005) Sliding hip screw fixation of trochanteric hip fractures: outcome of 1024 procedures. Injury 36:793-800

64. Matre K, Havelin LI, Gjertsen JE, Espehaug B, Fevang JM (2013a) Intramedullary nails result in more reoperations than sliding hip screws in two-part intertrochanteric fractures. Clin Orthop Relat Res 471:1379-1386

65. Matre K, Havelin LI, Gjertsen JE, Vinje T, Espehaug B, Fevang JM (2013b) Sliding hip screw versus IM nail in reverse oblique trochanteric and subtrochanteric fractures. A study of 2716 patients in the Norwegian Hip Fracture Register. Injury 44:735-742

66. Parker MJ, Handoll HHG (2010) Gamma and other cephalocondylic intramedullary nails versus extramedullary implants for extracapsular hip fractures in adults (Review). Cochrane Database Syst Rev. https://doi.org/10.1002/14651858.CD000093.pub5

67. Parker MJ (2017) Sliding hip screw versus intramedullary nail for trochanteric hip fractures; a randomised trial of 1000 patients with presentation of results related to fracture stability. Injury 48(12):2762-2767

68. Parker MJ, Raval P, Gjertsen JE (2018) Nail or plate fixation for A3 trochanteric hip fractures: a systematic review of randomised controlled trials. Injury 49(7):1319-1323

69. Palm H, Jacobsen S, Sonne-Holm S, Gebuhr P (2007) Integrity of the lateral femoral wall in intertrochanteric hip fractures: an important predictor of a reoperation. J Bone Joint Surg Am 89(3):470-475

70. Palm H, Lysén C, Krasheninnikoff M, Holck K, Jacobsen S, Gebuhr P (2011) Intramedullary nailing appears to be superior in pertrochanteric hip fractures with a detached greater trochanter. Acta Orthop 82(2):166-170

71. Norris R, Bhattacharjee D, Parker MJ (2012) Occurrence of secondary fracture around intramedullary nails used for trochanteric hip fractures: a systematic review of 13,568 patients. Injury 43:706-711 
72. Ban I, Birkelund L, Palm H, Brix M, Troelsen A (2012) Circumferential wires as a supplement to intramedullary nailing in unstable trochanteric hip fractures: 4 reoperations in 60 patients followed for 1 year. Acta Orthop 83:240-243

73. Palm H, Teixider J (2015) Proxial femoral fractures: can we improve further surgical treatment pathways? Injury Suppl 5:S47-S51

74. Fragility Fracture Network (2020). http://fragilityfracturenetwork.org. Accessed 15 Feb 2020

Open Access This book is licensed under the terms of the Creative Commons AttributionNonCommercial-NoDerivatives 4.0 International License (http://creativecommons.org/licenses/ by-nc-nd/4.0/), which permits any noncommercial use, sharing, distribution and reproduction in any medium or format, as long as you give appropriate credit to the original author(s) and the source, provide a link to the Creative Commons license and indicate if you modified the licensed material. You do not have permission under this license to share adapted material derived from this book or parts of it.

The images or other third party material in this book are included in the book's Creative Commons license, unless indicated otherwise in a credit line to the material. If material is not included in the book's Creative Commons license and your intended use is not permitted by statutory regulation or exceeds the permitted use, you will need to obtain permission directly from the copyright holder.

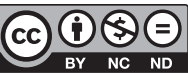

